Orbis Tertius, vol. XXVI, nº 34, e216, noviembre 2021 - abril 2022. ISSN 1851-7811

Universidad Nacional de La Plata

Facultad de Humanidades y Ciencias de la Educación

Centro de Estudios de Teoría y Crítica Literaria

\title{
Destino americano de Fray Marcos de Niza
}

\author{
Fray Marcos de Niza's American destiny
}

Aurora Díez-Canedo
aurora.diezcanedo@gmail.com
Universidad Nacional Autónoma de México, México

Recepción: 15 Abril 2021

Aprobación: 08 Agosto 2021

Publicación: 01 Noviembre 2021

Cita sugerida: Díez-Canedo, A. (2021). Destino americano de Fray Marcos de Niza. Orbis Tertius, 26(34), e216. https://doi.org/10.24215/18517811e216

\begin{abstract}
Resumen: Estudios recientes sobre la experiencia en Perú de Fray Marcos de Niza y su paso por Centroamérica antes de llegar a México, más la lectura de su Relación de la Jornada al Noroeste de la Nueva España en busca de ciudades y civilizaciones de supuestas grandes riquezas, permiten entender la coyuntura novohispana que hizo posible su designación para llevar a cabo casi por sí solo- una expedición larga y riesgosa, en la que estaban en juego intereses tanto de orden religioso y eclesiástico, como políticos y de gobierno, con protagonistas de la talla del virrey Mendoza, el conquistador Hernán Cortés y el propio Carlos V. El presente artículo busca redimensionar la figura de fray Marcos en la compleja y dinámica realidad virreinal de la primera mitad del siglo XVI y analiza las características y trascendencia de sus escritos.
\end{abstract}

Palabras clave: Fray Marcos de Niza, Franciscanos, Fray Juan de Zumárraga, Relación de Niza, Niza en la Brevísima relación.

Abstract: Recent studies about the experience of Fray Marcos de Niza in Peru and his journey through Central America before reaching Mexico, in addition to reading his Relación describing the journey to the New Spanish northwest in search for cities and civilizations of allegedly great riches, allow us to understand the circumstances in New Spain that led to his appointment to carry out (almost on his own) a long and risky expedition in which religious and ecclesiastical - as well as political and governmental - interests were at stake, involving political actors such as Viceroy Mendoza, the conqueror Hernán Cortés and Carlos V himself. The present article aims to redimention Fray Marcos's figure in the complex and dynamic colonial reality of the first half of the sixteenth century, and analyzes the characteristics and transcendence of his writings.

Keywords: Fray Marcos de Niza, Franciscans, Fray Juan de Zumárraga, Niza's Relación, Niza in the Brevísima relación.

\section{INTRODUCCIÓN}

La Relación escrita por fray Marcos de Niza sobre su expedición o “jornada” al Noroeste de México en 1539 ha tenido una trayectoria distinta de la de otras Relaciones novohispanas de la primera mitad del siglo XVI debido a que la mayoría tratan de la conquista, por un lado, y, por otro, a que es el único testimonio directo sobre dicha expedición. No obstante pertenecer a una orden religiosa, Fray Marcos parece sostenerse sobre 
su propia fuerza vital, y su Relación, comparada con otras de la época, un texto sui generis, "exagerado”, con una buena dosis de misticismo, inventado, o de plano "mentiroso".

La actuación de este franciscano forma parte de planes en los que él es una parte instrumental. Sin embargo, ocurre con aquella como con otras relaciones -en un principio "informes oficiales con una estructura y estilo muy marcados"-, y es que "las necesidades expresivas fueron desbordando todas estas convenciones..." (Motolinía, 2014, p. 271), dando como resultado testimonios de gran riqueza y valía, motivados tanto por la realidad que se tuvo enfrente y la calidad del informante, como por el destinatario o audiencia a quien iban dirigidas.

La mención en la Relación del nombre de Cibola, una de las primeras ciudades del recorrido de Fray Marcos, y en seguida, de "siete ciudades" ha derivado en identificar la Relación como de "las siete ciudades de Cíbola"; sin embargo, el texto carece de título y en la composición del sintagma con que suele denominarse a aquella se asocian dos "tradiciones" de distinto origen: una leyenda medieval sobre siete obispos portugueses que durante la invasión árabe salieron rumbo al oeste y en una isla fundaron sendas ciudades, y una palabra de los zuni de Nuevo México para la que existen dos etimologías: si: wolo, que es como llaman al búfalo, y $s h i$ wo-na, como se denomina al conjunto de pueblos de la tribu o cultura zuni (Craddock, 1999).

\section{NizA, LOS FRANCISCANOS DE MÉXICO Y EL CONTEXTO NOVOHISPANO}

La vida de Fray Marcos de Niza en lo que toca a su etapa novohispana está documentada en la obra de dos de sus hermanos de orden de la provincia del Santo Evangelio, fray Toribio de Motolinía y fray Jerónimo de Mendieta.

En la Historia de los indios de la Nueva España, Motolinía se refiere al recorrido de Niza; aunque no menciona su nombre es probable que se conocieran, pues eran además coetáneos, hasta donde la información -incierta respecto a las respectivas fechas de nacimiento- permite establecerlo:

En demanda de esta tierra habían salido ya muchas armadas, así por mar como por tierra, y de todos la escondió Dios y quiso que un pobre flaire descalzo la descubriese. El cual cuando trajo la nueva, al tiempo que lo dijo le prometieron que no la conquistarían a fuego y a sangre, como se ha conquistado casi todo lo que en esta tierra firme está descubierto, sino que se les predicaría el evangelio (2014, p. 185).

En el Libro Quinto de la Historia eclesiástica indiana "Que trata las vidas de los claros varones, apostólicos obreros de esta nueva conversión, que acabaron en paz con muerte natural”, escribe Mendieta sobre fray Marcos de Niza: "resultóle de aquella larga jornada una grave enfermedad de que quedó tullido hasta la muerte... Murió santamente en el convento de México, adonde está enterrado” (2002, p. 394).

Por otro lado, en Don fray Juan de Zumárraga, primer obispo y arzobispo de México Joaquín García Icazbalceta recoge una carta de Zumárraga a fray Marcos de 1546; Niza le responde, y le pide al obispo "limosna de un poco de vino" para su enfermedad (1947, pp. 263-265). También menciona Zumárraga a fray Marcos en una carta de fecha anterior ( 4 de abril de 1537) dirigida "a un eclesiástico desconocido", esta vez en relación con Perú:

...de prisa tomé al Fray Marcos que le tengo aquí en casa y le hice decir y firmar eso que verá vuestra merced que más lástima le porná que la carta que yo escribo al señor doctor Bernal, habiéndole en parte oído. Este padre es gran religioso digno de fé y aprobado en virtud de mucha religión y celo, al cual los fraires [sic] en el Perú eligieron por custodio, y cuando se fueron, y algunos acá aportaron, viendo los desafueros y crueldades de los que se dicen cristianos él me escribió de Guatimala, y yo le escribí que viniese acá y así vino, e yo le llevé al señor Visorrey y Su Señoría envió su relación a S.M. y a los de su Consejo y por estar él y todos tan ocupados en sermones y confesiones no le pude haber hasta agora y, aunque de prisa, van algunas pocas [cosasę?] que él refiere como testigo de vista y V. R. ha de dar un papel destos dos en su mano al Emperador nuestro señor comunicándolo con el señor doctor Bernal que persuadirá harto su corazón católico para que se quiten estas conquistas, que son oprobiosas injurias a nuestra cristiandad y fé católica...(García Icazbalceta, 1947, pp. 162-163). 
La Relación enviada por el virrey a la que se refiere el obispo de México, da cuenta de la importancia concedida al testimonio del franciscano que ha huido de Perú, el cual se vuelve una pieza crucial para abogar por formas de conquista más humanitarias y acordes con la religión católica.

Según Michel Nallino (investigador de origen francés, autor de Frère Marcos de Nice. A la poursuite de l'utopie Franciscaine aux Indes Occidentales. Edition Integrale), este "eclesiástico desconocido" no es otro que fray Bartolomé de las Casas, quien en 1537 dará a conocer -en latín- su "primera obra importante" Del único modo de atraer a los pueblos a la verdadera religión (Hanke, 1951, p. XIII), y más tarde incluirá en la Brevísima relación de la destrucción de las Indias, información sobre Perú a partir del testimonio de Niza (Nallino, 2012, pp. 104-105).

La figura de fray Marcos de Niza, con sus antecedentes peruanos, se vuelve notoria en la comunicación y planes del obispo de México con el defensor de los indios y el virrey Mendoza -si bien la participación de este último pudo no tener las mismas motivaciones que las de los religiosos-, para impedir que se siguieran llevando a cabo conquistas por la fuerza de las armas.

El presente trabajo busca contribuir a entender el momento y las razones que llevaron a elegir a fray Marcos de Niza para encabezar una conquista pacífica hacia el Norte de la México, habiendo otros franciscanos en la Nueva España.

El hecho de haber fray Marcos ocupado un lugar central en la expedición en busca de las llamadas "Siete Ciudades", así como la noticia de su testimonio sobre los sucesos de los conquistadores de Perú, y su posterior Relación de la expedición (1539), ameritan una revisión de los antecedentes del papel protagónico que le tocó desempeñar en la Nueva España.

\section{Vida de Fray Marcos de Niza, vice comisario en Perú}

Nacido en Niza -ciudad perteneciente al ducado de Saboya- hacia 1495, huérfano de padre y madre (García Icazbalceta, 1947, p. 263), Fray Marcos profesó como hermano en la provincia de San Luis (Aquitania, en el sur de Francia) y hacia 1530 partió a España. Según Nallino, Marcos hablaría italiano, francés, nizardo, latín y español o castellano. Poco después se embarca a las Indias occidentales, nombrado "vice comisario" en Perú por sus superiores; en una de dos flotas, ya sea con Francisco Pizarro en enero de 1531, o en marzo con Sebastián de Belalcázar, llega a Coaque, en la costa norte del actual Ecuador, tomada en posesión por Pizarro. ${ }^{2}$ Está presente en la toma de Cajamarca y en la captura y muerte de Atahualpa en 1532. En septiembre de 1533 regresa a Sudamérica, esta vez en la flota de Pedro de Alvarado que sale de Nicaragua, y busca reunirse con los conquistadores de Perú, Pizarro y Almagro, pero sin tocar tierra que pertenezca a la demarcación de Pizarro. Después de un complicado viaje por mar -en que una tormenta los obliga a desembarcar en una isla y a tirar por la borda a cerca de 80 caballos-, y de un igualmente intrincado recorrido por tierra a través de Los Andes nevados en que son sorprendidos por la erupción del volcán Cotopaxi, Pizarro se encuentra finalmente con Almagro entre Riobamba y Ambato. ${ }^{3}$ Fray Marcos desempeña el papel de mensajero entre Alvarado y Almagro cuando ambos conquistadores llegan a un acuerdo y Alvarado se retira de la conquista del Perú mediante una fuerte suma de dinero a cambio de su flota. (Flota que por lo demás no era necesaria para aquella conquista). Fray Marcos se queda y participa después en la conquista de Quito con Sebastián de Belalcázar.

Durante esta, en algún momento entre agosto y diciembre de 1534, Fray Marcos cristianiza y bautiza con el nombre de Marcos Duchicela a un pariente de Atahuallpa llamado Cachulima, que había tomado las armas para pelear al lado de Belalcázar contra el general rebelde Rumiñahui, quien había asesinado a la familia de Atahuallpa pretendiendo proclamarse su sucesor Inca. En el "principado" de Cacha, al sur de Perú, donde tiene lugar esta conversión mediante el bautismo, fray Marcos funda una parroquia de indios (Nallino, 2012, p. 67). 
Según Michel Nallino, fue gracias a Marcos Duchicela que Fray Marcos supo del origen del reino de Quito y la línea matrilineal de Atahuallpa, que lo convertía en heredero de los dos reinos: Quito y Cuzco. Con esta información, Niza escribió “Las dos líneas de los señores de Perú y Quito”, así como otro texto titulado "Ritos y ceremonias de los indios". ${ }^{4}$ Se demostraba así que Atahuallpa era heredero legítimo de Quito y no un usurpador y tirano, argumento usado por los españoles como justificación de conquista (de manera similar a como en la conquista de México se describe al gobierno de Moctezuma como una tiranía). Marcos Duchicela tenía interés en que los españoles lo reconocieran como descendiente de Atahuallpa.

A mediados de 1535, fray Marcos deja Perú y Ecuador y, en el camino de Guatemala, tiene un encuentro con fray Bartolomé de las Casas. En Guatemala, en septiembre de 1536, testifica en el proceso de residencia de Pedro de Alvarado, a favor del conquistador de Guatemala. También se entera, por una carta que envía Pizarro a Alvarado pidiendo refuerzos, de que ha habido un levantamiento en Perú y este está a punto de perderse (Vallejo García-Hevia, 2008, pp. 863-869).

Desde Guatemala, Fray Marcos le escribe al obispo Zumárraga y emprende el viaje a la Nueva España, donde ya se encontraban otros franciscanos que habían salido de Perú.

Cuando Niza emprende la Jornada de Cibola tendría 44 años. Según los testimonios de Zumárraga y posteriormente de Mendieta sabemos que estaba enfermo y que después de la expedición "quedó tullido hasta la muerte" (Mendieta, 2002, p. 394). Fray Marcos de Niza murió en marzo de 1558.

\section{Hernán Cortés y fray Marcos}

En enero de 1540, Hernán Cortés se embarca por segunda vez a España (Martínez Martínez, 2017, p. 28), uno de los motivos de este viaje fue "las diferencias con el virrey Mendoza" (p. 578). Al poco de llegar, con fecha del 25 de junio, escribe un Memorial al rey donde menciona a fray Marcos. Dice que lo conoció y que "entendía algo de cosas de navegación":

el dicho Fray Marcos habló conmigo estando yo en la Nueva España, e yo le di la noticia desta dicha tierra y descubrimiento della, porque tenía determinación de enviarlo en mis navíos en proseguimiento e conquista de la dicha costa e tierra, porque parescía que se le entendía algo de cosas de navegación... (Hernández Sánchez Barba, 1962, p. 407).

En la misma carta, el conquistador de México se queja amargamente ante Carlos V del "notorio agravio" que el virrey Mendoza le ha hecho impidiéndole la conquista de "cierta tierra" que está dentro de los límites de su demarcación según el contrato que firmó con el Rey en 1529, tierra que él ya ha descubierto y tomado la posesión, invirtiendo en ello mucho dinero y trabajos.

\footnotetext{
El dicho virrey -alega Cortés- ha querido dar color a la dicha fuerza y opresión que me ha hecho y hace, pretendiendo que diz que un Fray Marcos de Niza ha descubierto de nuevo la dicha tierra, siendo para ello enviado por el dicho visorey, en lo cual se ha hecho y hace siniestra relación a Vuestra Majestad (...) el cual dicho fraile lo comunicó con el dicho visorey, y con su licencia diz que fue por tierra en demanda de la misma costa e tierra que yo había descubierto, y que era y es de mi conquista; y después que volvió el dicho fraile ha publicado que diz que llegó a vista de la dicha tierra; lo cual yo niego haber él visto ni descubierto, antes lo que el dicho fraile refiere haber visto, lo ha dicho y dice por la sola relación que yo le había hecho de la noticia que tenía de los indios de la dicha tierra de Santa Cruz que yo truje, porque todo lo que el dicho fraile se dice que refiere, es lo mismo que los dichos indios a mí me dijeron; y en haberse en esto adelantado el dicho Fray Marcos fingiendo y refiriendo lo que no sabe ni vio, no hizo cosa nueva, porque otras muchas veces lo ha hecho y lo tiene por costumbre como es notorio en las provincias del Perú y Guatemala... (1962, pp. 407-408).
}

Queda claro que Cortés conocía los antecedentes de fray Marcos antes de su llegada a la Nueva España, y que en esta carta o memorial se propone desacreditar su Relación desde fecha muy temprana. Pero lo que más lo inquieta es la presencia de Vázquez de Coronado, que había llegado a la Nueva España con Mendoza y "era conocida la confianza que el virrey le tenía” (Ruiz Medrano, 1991, pp. 134-135). 
Posteriormente, Francisco López de Gómara en 2 capítulos de su Historia general de las Indias (1552) titulados "Sibola" y "Quivira", se refiere con ironía a estos lugares y ridiculiza a los religiosos, reforzando así al conquistador de México:

Las famosas Siete ciudades de Fray Marcos de Niza, que están en espacio de seis leguas, tendrán obra de 4 mil hombres. Las riquezas de su reino es no tener que comer ni qué vestir, durando la nieve siete meses (...). Viendo la poca gente y muestra de riqueza, dieron los soldados muy pocas gracias a los frailes que con ellos iban y que loaban la tierra de Sibola; y por no volver a México sin hacer algo ni las manos vacías, acordaron de pasar adelante, que les decían ser mejor tierra. [En Tiguex] tuvieron nueva de Axa y Quivira, donde decían que estaba un rey dicho por nombre Tatarrax, barbudo, cano, que ceñía un bracamarte, que rezaba en horas, que adoraba una cruz de oro y una imagen de mujer, señora del cielo. Mucho alegró y sostuvo esta nueva al ejército, aunque algunos la tuvieron por falsa y echadiza de frailes (1991, pp. 304-305).

Como escribe Bandelier, en el nuevo orden virreinal la noticia de las Siete ciudades representó una promesa de futuro tanto para los nuevos conquistadores y encomenderos como Francisco Vázquez de Coronado, como para los descendientes de los conquistadores, cuyas expectativas no se cumplían y formaban una población "flotante" (1905, p. VII).

\section{El documento de la Relación de Niza y su transmisión}

La Relación en busca de las siete ciudades se conserva de manera íntegra en el Archivo General de Indias de Sevilla en dos copias del siglo XVI.

En la medida en que la expedición en que participó Niza es el antecedente de la de Francisco Vázquez de Coronado, que llegó hasta lo que actualmente es el estado de Arizona y Kansas, la primera ha despertado el interés especialmente de los historiadores estadounidenses del "Spanish Southwest" o "American Southwest". En 1905, el antropólogo suizo-norteamericano Adolphe Bandelier dio a conocer en inglés la Relación de Niza traducida por su esposa y colega Fanny Bandelier; en los años treinta, el geógrafo e historiador Carl Sauer (1932) y Henry R. Wagner (1934), aportaron estudios pioneros sobre el tema. Quienes han publicado la Relación de fray Marcos de Niza en fecha reciente han sido también norteamericanos: Clive Hallenbeck (1987) y James R. Craddock, profesor emérito del departamento de Español y Portugués de la Universidad de Berkeley. Este último hizo la transcripción directamente del manuscrito que se encuentra en el Archivo General de Indias y lo publicó en un artículo en 1999 con exhaustivas notas histórico-filológicas. Craddock publica además, el facsímil del documento, integrado por 9 folios (recto y verso). ${ }^{5}$ 


\section{IMAGEN 1}

hoja final de la Relación con la firma de Fray Marcos.

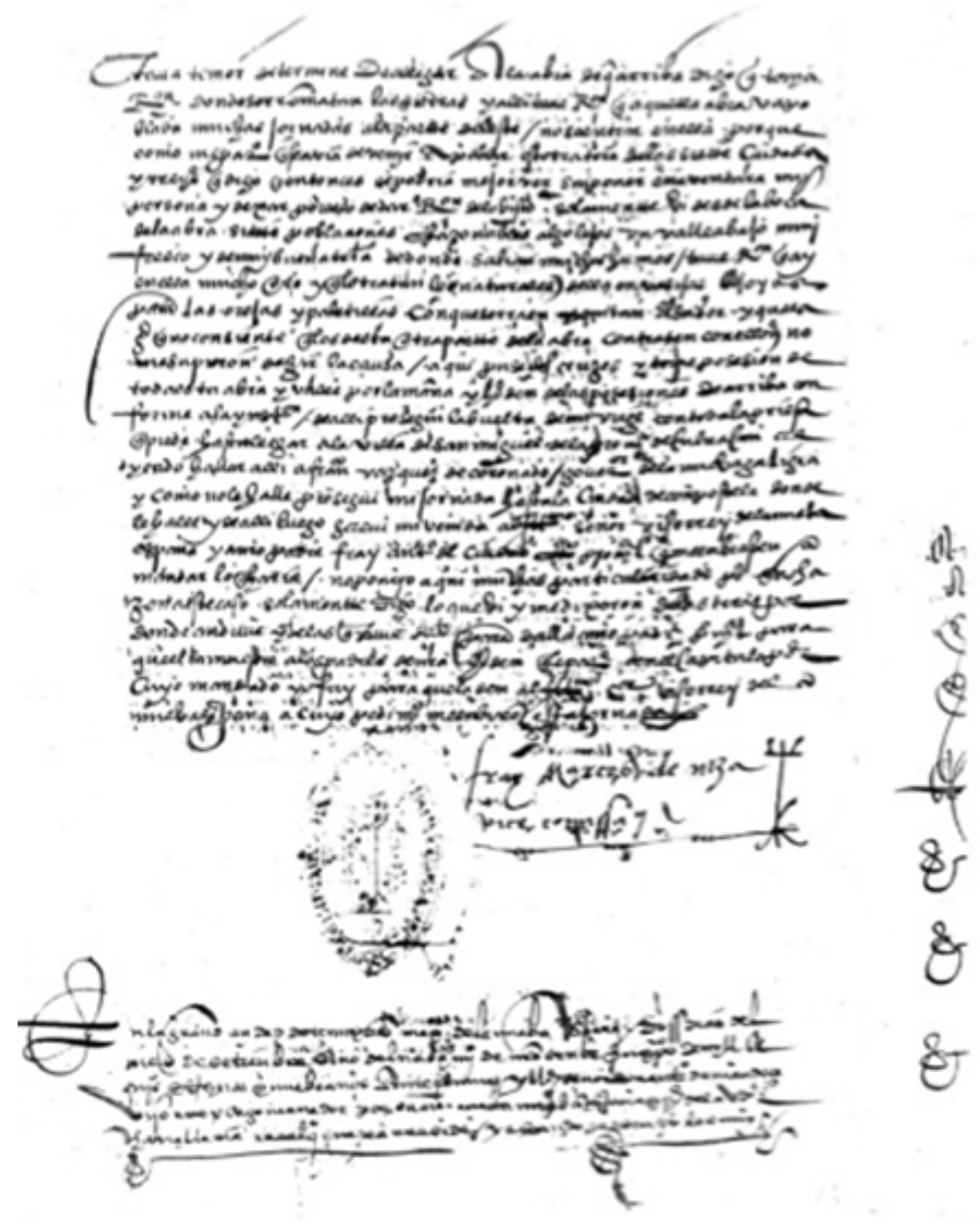

Solo en una de las copias (la que él denomina B1) aparece en una línea suelta la palabra Relación antes del comienzo del texto, el cual es un texto escrito de corrido, sin un título propiamente dicho, precedido de la "Instrucción".

Craddock menciona un documento del virrey Gaspar de Zúñiga y Acevedo de los primeros años del siglo XVII donde se dice que la Relación de Fray Marcos “anda impresa” (1999, p. 76), sin embargo, la primera publicación que se conoce es la incluida en traducción al italiano en el tercer volumen de la recopilación Navigazzioni et viaggi de Ramusio (1565, pp. 1555-1559), bajo el título Relatione del reverendo fra Marco de Nizza con divisiones a manera de capítulos. Posteriormente se publicó en español "caprichosamente modernizada" y no apta para fines filológicos según Craddock (1999), en la Colección de Documentos inéditos relativos al descubrimiento, conquista y organización de las antiguas posesiones españolas de América y Oceania (CDI) de Pacheco y Cárdenas (1865, pp. 325-351), a partir de una transcripción hecha en el siglo XVIII por Juan Bautista Muñoz. 


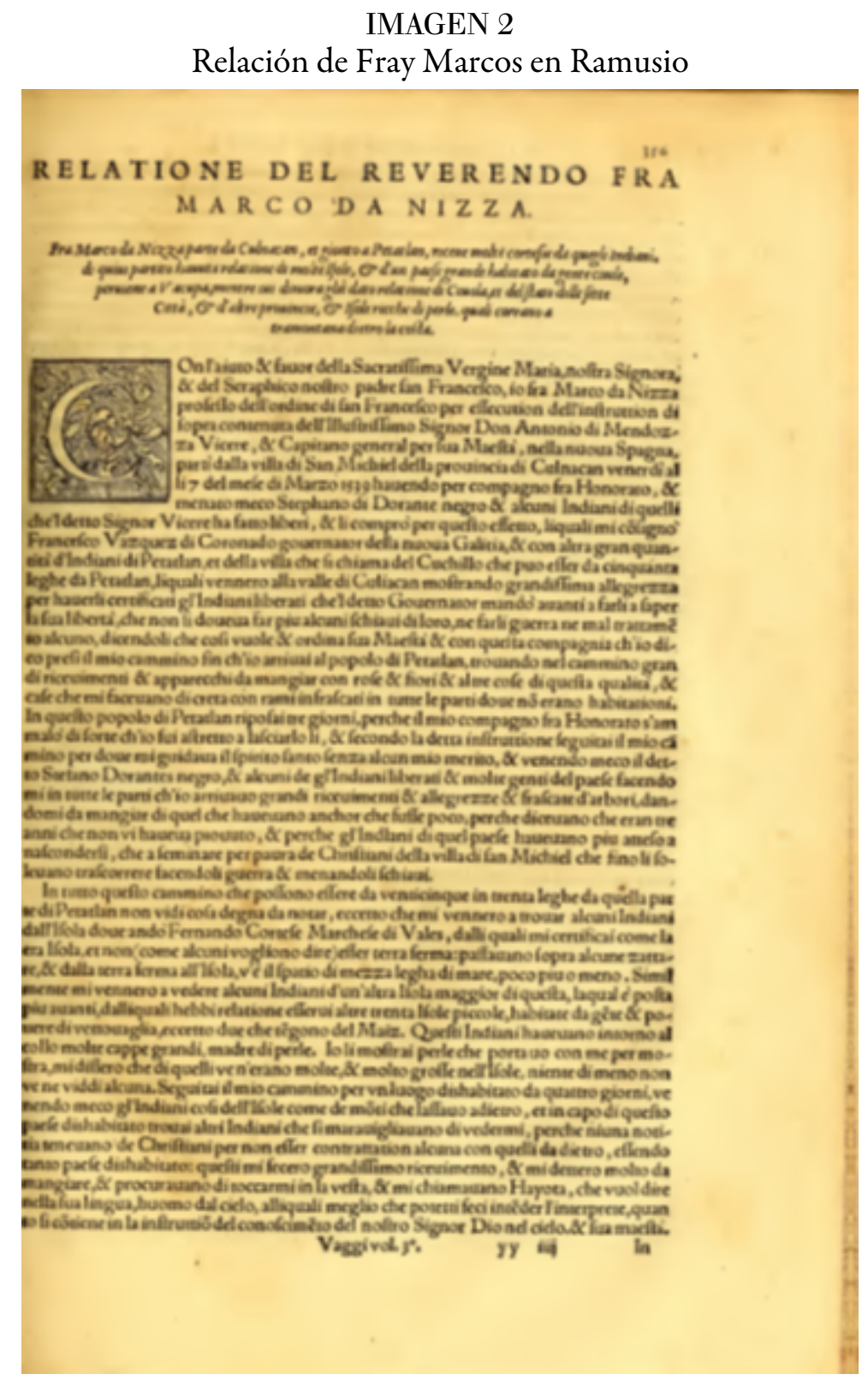

\section{La expedición en busca de las Siete ciudades de Cibola según la Relación de Niza}

El 20 de noviembre de 1538 en Tonalá, Nueva Galicia, Fray Marcos de Niza acusa recibo y firma la Instrucción del virrey Mendoza, la cual le entrega el gobernador Francisco Vázquez de Coronado. ${ }^{6}$

Provisto de su Instrucción y vestido con "vn abito de paño pardo que llaman de çar[a]goça que me hizo traer Francisco Vazquez de Coronado," (Niza en Craddock, 1999, p. 88), Fray Marcos inicia su recorrido desde la villa de San Miguel en Culiacán, acompañado de fray Honorato y del negro Esteban “de Dorantes" (p. 87); de varios indios que habían sido liberados por el virrey para poder participar en la Jornada, y de otros traídos de los pueblos cercanos de Petatlán y Cuchillo. El franciscano lleva consigo unas perlas de muestra y algunas piezas de oro. Fray Honorato se enferma al llegar a Petatlán y fray Marcos sigue el camino guiado por Esteban, que monta a caballo y lleva consigo "dos galgos de Castilla" (p. 88). Fray Marcos le manda tomar la delantera pues él va a un paso más lento. La llegada al pueblo de Vacapa coincide con la Semana santa; Niza toma un descanso y acuerda con Esteban el siguiente método de comunicación: 
que si tuuiese notiçia de tierra poblada y rrica que fuese cosa grande, 40 que no pasase adelantre, sino que boluiese en persona o me enbiase [fol. 4r] yndios con esta señal que conçertamos que si la cosa fuese rrazonable, me enbiase vna cruz blan[c]a de bn palmo y si fuese cosa grande, la enbiase de doss palmos y si fuese cosa mayor y mejor que la Nueva España, me enbiase vna gran cruz (p. 85).

En Vacapa llegan a ver a Fray Marcos unos indios de la costa y otros "yndios de los que llaman pintados, labrados los rrostros y pechos y braços” (p. 86) que le describen ciudades de gran riqueza. Pero Esteban nunca regresa, manda a indios mensajeros de su comitiva desde distintos puntos con noticias y cruces "de estatura de un hombre" (p. 85). En total, Fray Marcos recibe 3 grandes cruces. Al final, se encuentra a un indio que viene de regreso, malherido, con la noticia de que a una jornada de la primera de las Siete Ciudades, la persona que el señor tenía ahí puesta, al recibir la insignia de Esteban, con la que éste solía presentarse al llegar a cada población, consistente en un "calabaço [que] lleuaua vnas hileras de caxcaueles y dos plumas, vna blanca y otra colorada” (p. 91), la había tirado al suelo - "commo le dieron el calabaço y vido los caxcaueles, muy enojado arrojo en el suelo el calabaço y dixo, yo conozco esta gente porqu'estos caxcaueles no son de la hechura de los nuestros" (p. 92)-, y había amenazado al mensajero con matarlos a todos si entraban en la ciudad. Ellos no toman en serio la advertencia, siguen adelante y son encerrados en una casa grande; al tratar de escapar, los indios zunis los matan a flechazos. El que sobrevive, escribe Niza, era "hijo de un principal de los que venjan conmigo" (p. 91).

Fray Marcos enfrenta el descontento de los indios que lo acompañaban y teme por su vida. Decide continuar y llega "hasta la vista de Cibola" (p. 93) donde le informan que es la menor de las siete ciudades. Dice en su Relación ser aquella mayor que la ciudad de México, "que a mi ver es la mayor y mejor de todas las descubiertas" (p. 93); hace una sencilla toma de posesión colocando una cruz "delgada y pequeña” sobre un montón de piedras y bautiza al lugar: "paresçiome llamar aquella tierra el nuebo rreyno de san Francisco" (p. 93). Con temor de pasar más adelante a Totonteac, Acus y Maratta decide emprender el camino de regreso, confiado en que ha visto suficiente para hacer relación a las autoridades. ${ }^{7}$

Esta primera expedición es el antecedente de la gran expedición organizada por el virrey Antonio de Mendoza bajo el mando de Francisco Vázquez de Coronado, que comienza en febrero de 1540, donde también marcha fray Marcos acompañando a la armada. Al llegar en julio al pueblo de los zunis (Hawikuh) que habían matado al negro Esteban, ${ }^{8}$ ante la protesta de los españoles al encontrarse en medio de una comunidad de agricultores pobres, al fraile no le queda otra opción que dar vuelta atrás. Coronado toma posesión del pueblo y continúa su recorrido; no volverá sino hasta marzo de 1542, después de un recorrido de miles de kilómetros por el suroeste de los actuales Estados Unidos hasta llegar a Quivira, en el borde del río Arkansas, pero sin haber encontrado las riquezas que esperaban.

La atención en Fray Marcos se ha centrado en su Relación novohispana en busca de las Siete ciudades, sin embargo, según los testimonios de Zumárraga, Las Casas y posteriormente Velasco, no fue lo único que escribió.

\section{Fray Marcos y Fray Bartolomé}

La mayor proyección de Fray Marcos es sin duda el hecho de que varios párrafos de su "Información a la corte y obispo" aparezcan transcritos en la Brevísima relación de la destrucción de las Indias (1542) debido a la gran difusión que tuvo esta obra, si bien para su publicación en 1552 habrá que esperar 13 años. En el capítulo "De los grandes reinos y grandes provincias del Perú" de la Brevisima, se lee:

Yo, fray Marcos de Niza, de la orden de Sant Francisco, comisario sobre los frailes de la mesma orden en las provincias del Perú, que fue de los primeros religiosos que con los primeros cristianos entraron en las dichas provincias, digo dando testimonio verdadero de algunas cosas que yo con mis ojos vi en aquella tierra, mayormente cerca del tractamiento y conquistas hechas a los naturales. Primeramente, yo soy testigo de vista, y por experiencia cierta conocí y alcancé que aquellos indios del Perú es la gente más benívola que entre indios se ha visto, y allegada y amiga a los cristianos (...) Item, soy testigo 
y doy testimonio que sin dar causa ni ocasión aquellos indios a los españoles, luego que entraron en sus tierras, después de haber dado el mayor cacique Atabaliba, más de dos millones de oro a los españoles, y habiéndoles dado toda la tierra en su poder sin resistencia, luego quemaron al dicho Atabaliba, que era señor de toda la tierra... (Las Casas, 2014, p. 171).

Es gracias a Casas, que afirma tener "un traslado con su propia firma" (Las Casas, 2014, p. 171), que se conserva este informe de Fray Marcos, anterior a su Relación de las Siete ciudades, del que se tuvo conocimiento y circuló en la Nueva España.

Fray Bartolomé estuvo en España también en 1540 (Díaz del Castillo, 1992, p. 504).

\section{Posteridad de Niza}

En el siglo XVII, el presbítero español Fernando de Montesinos (m. en 1653), en su obra Memorias historiales, escrita a partir de los 15 años que vivió en Perú, pone en duda la credibilidad de las fuentes utilizadas por Bartolomé de las Casas, en especial a Fray Marcos, afirmando que se trata de un testimonio inventado por el dominico de principio a fin (Hyland, 2010, pp. 42-43). ${ }^{10}$

No es sino hasta el siglo XVIII que surgen otras obras de Fray Marcos de Niza escritas a raíz de su experiencia en Perú. Es Juan de Velasco, jesuita nacido en Riobamba en su Historia del reino de Quito, terminada en Faenza, Italia, en 1789, quien da total credibilidad a los siguientes escritos de Fray Marcos: Las dos lineas de señores de Perú y Quito; Historia de la conquista de la provincia del Perú; Historia de la conquista de la provincia de Quito; Ritos y ceremonias de los indios; Cartas informativas de la obra en las provincias de Perú y Quito. (Nallino, 2012, p. 40).

La Historia de Velasco no se publicó sino hasta 1840 y ninguno de estos textos se conserva.

Si se da crédito a Velasco, es probable que la información sobre Perú contenida en la Apologética historia sumaria de Bartolomé de las Casas esté basada en una o más de estas obras que el jesuita atribuye a Fray Marcos de Niza, como afirma Michel Nallino.

Ahora bien: según el escritor Benjamín Carrión, "[1]a Historia del reino de Quito es para los ecuatorianos como la leyenda del Cid para los españoles, como la de Rolando para los franceses, como la de los Nibelungos para los alemanes; su narrador es el primer novelista y el primer exaltador de esta nacionalidad" (Velasco, 1981, contraportada).

Para David A. Brading la Historia del reino de Quito es "la última gran crónica colonial compuesta dentro de las convenciones barrocas del patriotismo criollo"; según el historiador británico, en su rescate del pasado, a Velasco no le importó "inventar las fuentes" (1991, p. 455).

\section{REFERENCIAS}

Bandelier, A. F. (ed.) (1905). The Journey of Alvar Núñez Cabeza de Vaca and his companions from Florida to the Pacific 1528-1536. New York: A.S. Barnes and Company.

Bloom, L. D. (1941). Was Fray Marcos a Liar?. New Mexico Historical Review, 16 (2), 244-246.

Brading, D. A. (1991). Orbe indiano. De la monarquia católica a la república criolla 1492-1867. Traducción de Juan José Utrilla. México: FCE.

Craddock, J. R. (1999). Fray Marcos de Niza, Relación (1539): Edition and Commentary. Romance Philology, 53, 4-91. Recuperado de http://escholarship.org/uc/item/7pb6j8fx

Díaz del Castillo, B. (1992). Historia verdadera de la conquista de la Nueva España. México: Porrúa.

Dorantes de Carranza, B. (1987). Sumaria relación de las cosas de la Nueva España con noticia individual de los conquistadores y primeros pobladores españoles. México: Porrúa.

García Icazbalceta, J. (1947). Don fray Juan de Zumárraga. Primer obispo y arzobispo de México, R. Aguayo Spencer y A. Castro Leal (eds). México: Porrúa. 
Hallenbeck, C. (1987). The Journey of Fray Marcos de Niza. Introd. Texas: Southern Methodist University Press.

Hanke, L. (1951). Bartolomé de las Casas, historiador. En Fray Bartolomé de las Casas, Historia de las Indias. México: FCE.

Hernández Sánchez Barba, M. (1962). Hernán Cortés. Cartas y documentos. México: Porrúa.

Hyland, S. (2010). The Quito Manuscript: an Inca History Preserved by Fernando de Montesinos. New Haven: Yale University Publications in Anthropology/Yale Peabody Museum.

Las Casas, B. de (2014 [2005]). Brevisima relación de la destrucción de las Indias. Madrid: Alianza Editorial.

López de Gómara, F. (1991). Historia general de las Indias. Venezuela: Biblioteca Ayacucho.

Martínez, J. L. (1990). Hernán Cortés. México: Fondo de Cultura Económca/Universidad Nacional Autónoma de México.

Martínez Martínez, M. del C. (2015). Hernán Cortés en España (1540-1547): negocios, pleitos y familia. En M. F. Ríos Saloma (ed.), El mundo de los conquistadores. México: Universidad Nacional Autónoma de México, Instituto de Investigaciones Históricas/ Sílex ediciones. Disponible en https://www.historicas.unam.mx/publicaciones/pu blicadigital/libros/mundo/conquistadores.html

Martínez Martínez, M. del C. (2017). Martín Cortés. Pasos recuperados (1932-1962). Valladolid: Ediciones El Forastero/ Universidad de León, Instituto de Humanismo y Tradición clásica/ Centro de Estudios Mexicanos UNAM.

Mendieta, J. de (2002). Historia eclesiástica indiana. México: Conaculta.

Motolinía, T. de (2014). Historia de los indios de la Nueva España. Madrid: Real Academia Española, Centro para la Edición de los Clásicos Españoles.

Nallino, M. (2012). Frère Marc de Nice. A la poursuite de l'utopie franciscaine aux Indes Occidentales. Disponible en h ttp://www.archive.org/details/FrayMarcosdeNIzaInt

Pacheco, J. F. y Cárdenas, F. de (1865). Colección de Documentos inéditos relativos al descubrimiento, conquista y organización de las antiguas posesiones españolas de América y Oceania, volumen 3. Madrid: Imprenta de M. Bernaldo de Quirós. Disponible en http://bibliotecadigital.aecid.es/bibliodig/es/consulta/registro.cmd?id=11 18

Ramusio, G. B. (1565) Navigazione e viaggi, Vol. III. Disponible en: https://ia802604.us.archive.org/17/items/terzo volumedelle03ramu/terzovolumedelle03ramu.pdf

Ruiz Medrano, E. (1991). Gobierno y sociedad en Nueva España: Segunda audiencia y Antonio de Mendoza. Zamora, Mich.: El Colegio de Michoacán.

Sauer, C. O. (1932). The Road to Cibola. Berkeley: University of California Press.

Vallejo García-Hevia, J. M. (2008). Pedro de Alvarado. Juicio a un conquistador. Su proceso de residencia en Guatemala. Madrid: Marcial Pons Historia.

Velasco, J. de (1981). Historia del reino de Quito en la América meridional. Venezuela: Biblioteca Ayacucho.

Wagner, H. (1934). Fray Marcos de Niza. New Mexico Historical Review, 9(2), 184-227.

\section{Notas}

1 Cf. por ejemplo Lansing D. Bloom "Was Fray Marcos a Liar?" (1941). José Luis Martínez se refiere a "exagerados relatos" (1990, p. 731).

2 Francisco Pizarro obtiene el 26 de julio de 1529 de Carlos V la capitulación que lo nombra gobernador vitalicio y capitán general de Perú, denominado entonces "Nueva Castilla".

3 Cf. un mapa de este recorrido en Nallino (2012, p. 59).

4 Es Juan de Velasco, jesuita nacido en Riobamba, autor de la Historia del reino de Quito escrita en Faenza, Italia, después de la expulsión de la Orden, quien afirma que fray Marcos escribió 5 textos: Las dos líneas de señores de Perú y Quito; Historia de la conquista de la provincia del Perú; Historia de la conquista de la provincia de Quito; Ritos y ceremonias de los indios; Cartas informativas de la obra en las provincias de Perú y Quito. Sin embargo, Velasco es el único que dice haber conocido los textos de Niza. 
5 Explica Craddock (1999) que existen dos copias manuscritas del siglo XVI de la Relación de Fray Marcos de Niza (legajo Patronato 20, núms. 10a y 10b). Las citas textuales en el presente texto corresponden a las páginas de dicho artículo. Actualmente puede consultarse en el Portal de Archivos Españoles, PARES.

6 La Instrucción establece ganarse a los indios mediante buen trato, vigilar el comportamiento de Coronado, dejar aviso -especialmente cerca de la costa del mar del Sur- en cartas enterradas debajo de árboles grandes y marcados con una cruz para que puedan reconocerse desde los navíos, y tomar posesión de las tierras, principalmente. En el documento completo, se incluye después del acuse de fray Marcos, la "certificación" final del 26 de agosto de 1539, firmada por fray Antonio de Ciudad Rodrigo, entonces ministro provincial de la provincia del Santo Evangelio de la Nueva España, quien afirma haberse ejecutado fielmente la Instrucción.

7 Cf. un mapa del recorrido de Fray Marcos en Nallino (2012, p. 79).

8 A Esteban lo matan en Chichilticalli (“Casa Grande”), antes de llegar a Cíbola (Nallino, 2012, p. 72).

9 Según Nallino (2012, p. 72 y p.118), este texto, "Información a la corte y al obispo" se leyó en público en presencia del virrey de la Nueva España en septiembre de 1537.

10 Agradezco la información a la Dra. Patricia Escandón Bolaños. 